\title{
O USO DO FMEA COMO FERRAMENTA DE AVALIAÇÃO DOS ASPECTOS E IMPACTOS AMBIENTAIS NUMA INDÚSTRIA DE MICROELETRÔNICA
}

\section{THE USE OF FMEA AS A TOOL FOR EVALUATING THE ENVIRONMENTAL ASPECTS AND IMPACTS IN THE MICROELECTRONICS INDUSTRY}

\author{
Leandro Nascimento de Oliveira ${ }^{1}$; Lúcia Santana de Freitas ${ }^{2}$ \\ ${ }^{1}$ Universidade Federal de Campina Grande - UFCG - Campina Grande - Paraíba - Brasil \\ inforleo@gmail.com \\ ${ }^{2}$ Universidade Federal de Campina Grande - UFCG - Campina Grande - Paraíba - Brasil \\ luciasf@ch.ufcg.edu.br
}

\begin{abstract}
Resumo
Este artigo tem como objetivo identificar os aspectos e impactos ambientais de uma indústria de microeletrônica à luz da ferramenta de Análise dos Modos de Falhas e seus Efeitos (FMEA). Na fundamentação teórica, mostra-se que a FMEA pode ser adaptada para este fim de forma a analisar os pontos em que uma empresa pode causar danos ambientais, e quais medidas devem ser tomadas para mitigar tais danos Quanto à metodologia utilizada, a pesquisa caracteriza-se como exploratória e descritiva, utilizando-se do método de estudo de caso. Os dados foram tratados de forma qualitativa e quantitativa, através dos parâmetros elaborados com o intuito de mensurar os impactos ambientais, para uso com a ferramenta FMEA. Através da aplicação da ferramenta, foi constatado que a empresa estudada realiza o descarte de diversos tipos de resíduos de produtos químicos, eletrônicos, de embalagens e de materiais usados nos seus dois processos industriais, gerando 13 tipos de aspectos, sendo 6 considerados como de baixa intensidade, 3 de média ou moderada intensidade e 4 de alta intensidade, dentre os quais 2 dos resíduos e impactos potenciais não são eliminados adequadamente, 6 são eliminados parcialmente, e 5 são eliminados totalmente.
\end{abstract}

Palavras-chave: práticas ambientais; FMEA; aspectos e impactos ambientais; microeletrônica.

\section{Introdução}

O setor de eletroeletrônica vem conseguindo altos índices de crescimento nos últimos anos. Segundo Puga e Junior (2011), este apresenta uma perspectiva de investimento de R \$ 33 bilhões entre os anos de 2011 e 2014, e crescimento de 8,2\% frente ao período de 2006 a 2009.

Grande parte desse crescimento é decorrente da criação de uma infraestrutura de pesquisa e ensino de pós-graduação nas áreas de ciência e tecnologia, pelo aumento do aquecimento no mercado de trabalho, expansão do crédito as pessoas físicas, aumento dos 
níveis de confiança do consumidor, políticas de transferência de renda, maior acesso da população a bens eletrônicos, crescente uso de telefonia, necessidades de equipamentos na área de exploração de petróleo, desenvolvimento do setor de energia elétrica e automotivo, aliados a implantação de Programas Governamentais como o PNBL - Plano Nacional de Banca Larga, e a UCA - Um Computador por Aluno, entre outros.

Para Tavares (2001), a aplicação dos diversos incentivos no país, permitiu a instalação de muitos empreendimentos nos setores de informática, telecomunicação e eletrônica de consumo, de forma que atendessem a maior parte da demanda interna por produtos acabados, porém com elevado conteúdo de importações e poucas exportações. O setor de eletrônica de consumo opera quase que totalmente instalado na Zona Franca de Manaus, com exceções no Estado de São Paulo, e engloba os segmentos de vídeo, áudio e alguns outros produtos. Em termos de qualidade, esse segmento tem conseguido oferecer ao mercado interno produtos de qualidade semelhante aos produtos internacionais, porém com preços pouco competitivos devido à carga tributária, que acaba influenciando também na capacidade de exportação do país.

Entretanto, todo o crescimento do setor eletroeletrônico traz consigo um grave problema que começa a ganhar espaço para discussões, relacionado ao destino do chamado "lixo eletrônico". Esse lixo contém substâncias tóxicas como o mercúrio, cádmio e chumbo, que podem contaminar o meio ambiente, e seu gerenciamento pressiona as empresas geradoras a buscar soluções para seu controle e descarte. De acordo com Aguilar (2009), os resíduos eletrônicos representam em torno de $5 \%$ de todo o lixo produzido pela humanidade, cerca de 50 milhões de toneladas de eletrônicos são descartadas por ano em todo o mundo. O Brasil produz em média $2,6 \mathrm{Kg}$ de lixo eletrônico por habitante, o equivalente a menos de $1 \%$ a produção mundial de resíduos, porém, este número está aumentando.

Segundo Santos e Souza (2009) até o ano de 2004 foram descartados cerca de 315 milhões de microcomputadores em todo o mundo. No Brasil, neste mesmo período, houve o descarte de cerca de 1 milhão de equipamentos. Isto causa, além da ocupação de grandes espaços, o problema da toxidade de alguns metais pesados que contidos nos equipamentos.

Além de todos os materiais que compõem os aparelhos eletrônicos, têm-se também aqueles materiais utilizados no processo de transformação, como óleos para motores, gases expelidos por máquinas, água utilizada em processos de limpeza, dentre outros. Estes materiais indiretos também causam danos ao meio ambiente, e devem ser tratados de maneira adequada, de forma a atender a legislação vigente.

De acordo com Aguilar (2009), o chumbo, o mercúrio, o cádmio, o cromo e o arsênio são metais componentes de computadores que, naturalmente, não fazem parte de nenhum organismo, e não desempenham funções nutricionais e nem bioquímicas, em microorganismos, 
plantas ou animais. Assim, sua presença ou contato com organismos vivos é extremamente prejudicial. Sua disposição em lixões comuns acaba contaminando o solo e a água. Sua extração do meio ambiente já causa danos, desde o transporte, até o uso de água na fabricação dos bens finais. O mercúrio é muito utilizado em computadores, monitores e TVs com tela plana pode causar danos cerebrais e ao fígado. O chumbo, também muito utilizado, pode causar náuseas, perda de coordenação e memória, podendo levar à morte.

Diante deste contexto, se levanta o seguinte problema de pesquisa: Quais os aspectos e impactos ambientais de uma indústria de microeletrônica? Como forma se responder a problemática, o presente trabalho tem como objetivo identificar os aspectos e impactos ambientais numa indústria de microeletrônica à luz da ferramenta FMEA.

\section{Fundamentação teórica}

Com o intuito de avaliar os impactos ambientais de uma atividade, podem-se usar diversas ferramentas similares à Avaliação de Impacto Ambiental com o mesmo intuito de avaliar em que pontos um empreendimento pode causar danos ambientais, e quais medidas devem ser tomadas para mitigar tais problemas. Dessa forma, tem-se a ferramenta de Análise dos Modos de Falhas e seus Efeitos, derivado do inglês Failure Mode and Effects Analysis, mais conhecido pela sigla FMEA.

De acordo com Matos e Milan (2009), a FMEA é uma ferramenta gerencial desenvolvida em 1949 por militares americanos, como objetivo de determinar o efeito da ocorrência de falha em sistemas e em equipamentos do exército americano. Na década de 60, foi desenvolvida e aprimorada pela NASA - Administração Nacional de Aeronáutica e Espaço, quando foi tomando espaço nos setores aeronáuticos. A partir de 1988, esta ferramenta começou a ser utilizada em empresas como a Ford e General Motors em seus programas avançados de planejamento da qualidade em projetos e processos.

\subsection{FMEA aplicada à gestão ambiental segundo Andrade e Turrioni (2000) e Vandenbrande} (1998)

Andrade e Turrioni (2000) e Vandenbrande (1998) expõem um modelo de análise dos aspectos e impactos ambientais através da utilização do FMEA, onde descrevem os passos da sistemática de utilização da FMEA no Sistema de Gestão Ambiental de uma empresa: Passo 1: Definição da equipe responsável; Passo 2: Definição dos itens do Sistema de Gestão Ambiental que serão considerados; Passo 3: Preparação prévia para coleta de dados; Passo 4: Pré-filtragem dos aspectos ambientais considerados; Passo 5: Identificação do processo/função a ser analisado; Passo 6: Identificação dos aspectos e impactos ambientais; Passo 7: Identificação das 
causas das falhas; Passo 8: Identificação dos controles atuais de detecção das falhas ou causas;

O Passo 9: Determinação dos índices de criticidade; Corresponde às colunas "G”, "O", "D" e "IRA" onde: "G" Gravidade do Impacto parte de uma análise do efeito do risco para avaliação de sua gravidade, que é estimado em uma escala de 1 a 10. Trata-se da gravidade do impacto ambiental do modo potencial de falha relativo ao meio ambiente. Uma redução no índice de gravidade pode ser conseguida através de uma alteração do projeto do produto/processo; "O” Ocorrência da Causa parte de uma análise do efeito do risco para avaliação de sua probabilidade de ocorrência, com base em uma escala de 1 a 10; "D" Grau de Detecção parte de uma análise de uma causa do risco para avaliação do grau de controle possível de ser exercido sobre ele, sendo estimado em uma escala de 1 a 10. "IRA" Índice de Risco Ambiental é obtido pela multiplicação dos índices anteriores, e fornece uma escala hierarquizada da relevância de cada produto/processo/função analisados, podendo variar entre 1 e 1.000 .

Passo 10: Análise dos riscos ambientais e plano de ações Passo 11: Revisão do plano de ação; e, Passo 12: Revisão do FMEA sempre que necessário. Segundo Andrade e Turrioni (2000) cabe à empresa definir a periodicidade destas análises. Dessa forma, o FMEA pode ser utilizado na definição de aspectos e impactos ambientais nos diversos tipos de atividades e empresas existentes.

\section{Aspectos metodológicos}

Segundo Vergara (2009) quanto aos fins, esta pesquisa é classificada como exploratória pelo fato de estudar uma indústria de microeletrônica, onde são escassos estudos abordando os aspectos, impactos e práticas ambientais em tal indústria, e, descritiva, pois se faz a descrição dos processos da organização e seus respectivos aspectos e impactos ambientais, através da utilização da ferramenta FMEA. Quanto aos meios, um estudo de caso, pois permite um amplo detalhamento e conhecimento da empresa estudada, através de um estudo profundo de seu processo produtivo.

Assim, o caso estudado foi na Empresa X, situada na cidade de Campina Grande, que trabalha com a produção e comercialização de microcomputadores, microcomputadores portáteis e placas de circuito impresso, portanto inserida na área de microeletrônica e propensa a gerar resíduos nocivos ao meio ambiente.

As fontes utilizadas no estudo foram primárias e secundárias, como fontes primárias se utilizou de um roteiro de entrevista semi-estruturada, focado nas etapas do processo produtivo, de forma a descrever todo o processo, os impactos referentes a cada etapa e as práticas adotadas em relação à questão ambiental, foram entrevistados - Diretor Industrial, Gerente de Produção e dois Supervisores. Com base nessas informações foi elaborado um 
questionário e aplicado às mesmas pessoas com questões focadas na FMEA, conforme Quadro 1 Também se utilizou da observação participante, uma vez que um dos autores trabalha na empresa há cinco anos. Quanto às fontes secundárias de pesquisa, foram utilizados documentos, relatórios, manuais, formulários, dentre outros. As informações foram obtidas no período de 2 a 13 de Maio de 2011, respeitando a disponibilidade da empresa e dos entrevistados.

Quanto à análise se deu de forma qualitativa no que diz respeito à identificação do processo produtivo, impactos e práticas ambientais da empresa, de forma a serem analisados utilizando a ferramenta FMEA, e, quantitativa, através da utilização da ferramenta FMEA, de forma a caracterizar e avaliar de forma quantitativa os aspectos e impactos gerados pela empresa.

Quadro 1 - Modelo de tabela da ferramenta FMEA utilizada na pesquisa

\begin{tabular}{|c|c|c|c|c|c|c|c|c|c|}
\hline $\begin{array}{l}\text { LOGO DA } \\
\text { EMPRESA }\end{array}$ & & & \multicolumn{6}{|c|}{ DESCRIÇÃO DO FORMULÁRIO FMEA } & $\begin{array}{c}\text { No DOC.: }^{\circ} \\
\text { PÁG.: } \\
\text { REV } .\end{array}$ \\
\hline \multicolumn{10}{|c|}{ ASSUNTO: IDENTIFICAÇÃO E AVALIAÇÃO DOS ASPECTOS E IMPACTOS } \\
\hline \multirow[b]{2}{*}{$\begin{array}{l}\text { Etapa do } \\
\text { Processo }\end{array}$} & \multirow[b]{2}{*}{$\begin{array}{c}\text { Resíduo } \\
\text { Gerado }\end{array}$} & \multirow[b]{2}{*}{$\begin{array}{c}\text { Causa } \\
\text { Potencial }\end{array}$} & \multicolumn{2}{|c|}{ Identificação } & \multicolumn{2}{|c|}{ Avaliação } & \multirow[b]{2}{*}{$\begin{array}{l}\text { Intensi- } \\
\text { dade do } \\
\text { Impacto }\end{array}$} & \multirow[b]{2}{*}{$\begin{array}{c}\text { Ação de } \\
\text { Controle ou } \\
\text { Contenção }\end{array}$} & \multirow[b]{2}{*}{$\begin{array}{l}\text { Ações da } \\
\text { Empresa }\end{array}$} \\
\hline & & & Aspectos & Impactos & $\sum L>$ & 究 & & & \\
\hline
\end{tabular}

Fonte: Elaboração própria baseada nos modelos desenvolvidos por Andrade e Turrioni (2000)

O Quadro 1 mostra a ferramenta FMEA adaptada a partir do modelo desenvolvido por Andrade e Turrioni (2000), os campos foram preenchidos conforme os requisitos abaixo:

a) Etapa do processo: Inserir o nome da etapa do processo responsável pela geração do resíduo, e identificar o processo produtivo no qual está incluído;

b) Resíduo gerado: Inserir o resíduo gerado pela atividade;

c) Causa potencial: Descrição da ação que possa resultar na geração dos resíduos;

d) Identificação: aspectos: Elemento resultante do processo da empresa que possa i nteragir com o meio ambiente. Neste caso, insere-se a descrição da ação. Ex.: Descarte de papel/papelão; Impactos: Modificação do meio ambiente resultado da ação dos processos da empresa. Neste caso, insere-se o resultado dos aspectos no meio ambiente;

e) Avaliação: feita pelos critérios: magnitude, frequência e volume, bem como, o cálculo do IRA ou total, dado pela soma dos critérios anteriormente descritos $(\mathrm{M}+\mathrm{F}+\mathrm{V}$.).

O critério Magnitude representa a gravidade do impacto, considerando sua abrangência espacial (dimensão do dano) e reversibilidade (capacidade de remediar), podendo ser pontuado conforme mostra o Quadro 2. 
Quadro 2 - Critérios para pontuação da magnitude dos impactos ambientais

\begin{tabular}{|c|c|c|}
\hline Magnitude & Critério & Pontuação \\
\hline Baixa & $\begin{array}{c}\text { Impacto desprezível/restrito ao local de ocorrência, reversível com ações imediatas, sem } \\
\text { possibilidade de danos pessoais. }\end{array}$ & 1 \\
\hline Média & $\begin{array}{c}\text { Impacto considerável ao local de ocorrência, reversível com ações mitigadoras, com } \\
\text { danos pessoais reversíveis. }\end{array}$ & 2 \\
\hline Alta & $\begin{array}{c}\text { Impacto de grande extensão e/ou conseqüência irreversíveis, mesmo com ações } \\
\text { mitigadoras, com danos pessoais irreversíveis. }\end{array}$ & 3 \\
\hline
\end{tabular}

Fonte: Elaboração própria baseada nos modelos desenvolvidos por Andrade e Turrioni (2000)

Enquanto que a Frequência representa a probabilidade de ocorrência do impacto, podendo ser pontuada conforme demonstrado no Quadro 3.

\begin{tabular}{|c|c|c|}
\multicolumn{2}{|c}{ Quadro 3 - Critérios para pontuação da frequência dos impactos ambientais } \\
\hline Frequência & Critério & Pontuação \\
\hline Baixa & Impacto improvável de ocorrer. & 1 \\
\hline Média & Impacto provável de ocorrer. & 2 \\
\hline Alta & Impacto esperado que ocorra & 3 \\
\hline
\end{tabular}

Fonte: Elaboração própria baseada nos modelos desenvolvidos por Andrade e Turrioni (2000)

Quanto ao volume, este representa a quantidade do resíduo gerado no mês, podendo ser pontuada conforme explicitado no Quadro 4.

Quadro 4 - Critérios para pontuação do volume dos resíduos

\begin{tabular}{|c|c|c|}
\hline \multirow{2}{*}{ Volume } & Critério & \multirow{2}{*}{ Pontuação } \\
\hline \multirow{2}{*}{ Baixo } & Resíduo gerado menor que 499Kg (VOL<499) mensais. & \multirow{2}{*}{1} \\
\cline { 2 - 2 } & Resto de óleo usado do compressor menor que 5L (VOL<5L) mensais. & \multirow{2}{*}{2} \\
\cline { 2 - 2 } Médio & Resíduo gerado maior que 500Kg e menor que 1.999Kg (500<VOL<1999) & \multirow{2}{*}{3} \\
\cline { 2 - 3 } & Resto de óleo usado maior que 5L e menor que 10L (5L<VOL<10L) & \\
\cline { 2 - 2 } Alto & Resíduo gerado maior que 2.000Kg (VOL<2000) mensais. & \\
\cline { 2 - 3 } & Resto de óleo usado maior que 10L (VOL<10L) mensais. & \\
\hline
\end{tabular}

Fonte: Elaboração própria baseada nos modelos desenvolvidos por Andrade e Turrioni (2000)

f) Intensidade do impacto: Preenchido conforme o resultado apresentado no item Total. Caso o resultado esteja entre 1 e $3(1 \leq$ TOTAL $\leq 3)$, o campo será preenchido com o termo "Baixa", pois sua classificação conforme os critérios indicam magnitude, volume e freqüência baixas, representando um impacto pequeno ou nulo. Caso o Total tenha um resultado entre 4 e 6 $(4 \leq$ TOTAL $\leq 6)$, este campo deve ser preenchido com o termo "Média ou Moderada", pois este total indica que algum dos critérios apresentou um nível médio, sendo suficiente para que sejam tomadas ações de contenção ou controle. Caso o Total tenha um resultado entre 7 e 9 (7 $\leq$ TOTAL $\leq 9)$, este campo deve ser preenchido com o termo "Alta", pois este total indica que algum dos critérios apresentou um nível alto, necessitando de medidas especiais de ação de contenção ou controle.

g) Ação de controle ou contenção: Ação para controlar ou mitigar o impacto ambiental de algum aspecto, proveniente das atividades geradoras. Devem-se inserir também as práticas 
ambientais recomendadas para o tratamento do impacto ambiental, baseadas nas especificações de cada tipo resíduos, em instruções contidas nas embalagens dos produtos, e em documentações provenientes dos fornecedores, a exemplo da FISPQ (Ficha de Informações de Segurança de Produto Químico), entre outros.

h) Ações da empresa: Apresentar as ações que já são tomadas pela empresa em relação aos impactos descritos, ou as ações que estão em processo de implantação.

\section{Apresentação e análise dos resultados}

\subsection{A empresa}

A Empresa X foi fundada no ano de 2005, e atua principalmente na região Nordeste do País, sua unidade fabril está localizada em Campina Grande, Estado da Paraíba, sua unidade comercial está localizada na cidade de Recife-PE. Produz equipamentos de informática, dentre os quais estão microcomputadores, microcomputadores portáteis e placas de circuito impresso, comercializando também diversos periféricos como monitores e impressoras. Em 2007 a empresa alcançou a certificação segundo a NBR ISO 9001:2000 do seu processo de montagem e comercialização de microcomputadores, tendo seu sistema migrado em 2009 para a nova versão da Norma NBR ISO 9001:2008, e a extensão do seu escopo de certificação para: Montagem e comercialização de microcomputadores e microcomputadores portáteis.

No ano de 2009 implantou mais um processo de montagem, a linha de montagem SMD e PTH, para produção de placas de circuito impresso, visando atender sua demanda interna e futuramente a demanda externa, evidenciando cada vez mais a busca pela constante atualização tecnológica da empresa e um melhor posicionamento no mercado. Em 2010 este novo processo de montagem foi incluído no escopo de certificação ISO 9001:2008.

A partir da crescente preocupação mundial com as questões ambientais, conforme as exigências legais e a visualização dos seus processos internos como geradores de resíduos perigosos para o meio ambiente, a empresa iniciou a implantação de um Sistema de Gestão Ambiental integrado ao Sistema de Gestão da Qualidade, passando a ser chamado por Sistema de Gestão da Qualidade e Meio Ambiente.

\subsection{Etapas dos processos produtivos e seus respectivos impactos}

Com base nos dados obtidos, chegou-se a uma definição dos processos produtivos e dos seus respectivos aspectos e impactos ao meio ambiente. A empresa possui dois processos produtivos, sendo o primeiro voltado para a produção de placas de circuito impresso, denominado Produção SMD/PTH (Quadro 5), e o segundo voltado para a produção de microcomputadores e microcomputadores portáteis, denominado Produção Fine Assembly 
(Quadro 6):

O processo de produção de placas de circuito impresso, ou Produção SMD/PTH, e os aspectos e impactos resultantes estão discriminados no Quadro 5.

Quadro 5 - Etapas do processo produtivo de placas de circuito impresso

\begin{tabular}{|c|c|c|c|}
\hline Etapas & Descrição & Aspectos & Impactos \\
\hline $\begin{array}{l}\text { 1. Recebimento } \\
\text { de material }\end{array}$ & $\begin{array}{c}\text { A matéria prima a ser utilizada, bem como os } \\
\text { produtos químicos necessários para fabricação } \\
\text { são recebidos, separados e organizados de } \\
\text { forma a estarem preparados para alimentar as } \\
\text { máquinas e postos de trabalho. }\end{array}$ & $\begin{array}{c}\text { Descarte de } \\
\text { papel/papelão, isopores, } \\
\text { espumas e plástico das } \\
\text { embalagens das matérias } \\
\text { primas. }\end{array}$ & $\begin{array}{l}\text { Alteração da qualidade } \\
\text { do solo. } \\
\text { Prejuízo para a fauna e } \\
\text { flora. }\end{array}$ \\
\hline $\begin{array}{c}\text { 2. Alimentação } \\
\text { de máquinas e } \\
\text { postos de trabalho }\end{array} \mid$ & \begin{tabular}{|c|} 
Os componentes eletrônicos são \\
colocados nas máquinas de inserção de \\
componentes, e os postos de trabalho são \\
abastecidos com os materiais apropriados. \\
Produtos químicos como soldas são colocados \\
no nas máquinas e fornos.
\end{tabular} & - & - \\
\hline $\begin{array}{l}\text { 3. Máquina de } \\
\text { inserção de } \\
\text { componentes }\end{array}$ & $\begin{array}{l}\text { A placa “nua” é inserida na máquina de } \\
\text { inserção de componentes, os quais são } \\
\text { inseridos e fixados através da placa, sendo } \\
\text { presos por uma pasta de solda. }\end{array}$ & $\begin{array}{l}\text { Descarte de resíduos de } \\
\text { pasta de solda. }\end{array}$ & $\begin{array}{l}\text { Alteração da qualidade } \\
\text { do solo e da água. } \\
\text { Prejuízo para a saúde } \\
\text { humana, fauna e flora. }\end{array}$ \\
\hline $\begin{array}{l}\text { 4. Máquina de } \\
\text { revisão }\end{array}$ & $\begin{array}{l}\text { A máquina revisa a placa com os componentes } \\
\text { inseridos de forma a identificar problemas com } \\
\text { o processo de inserção. }\end{array}$ & - & - \\
\hline 5. Forno 1 & $\begin{array}{c}\text { A placa com os componentes inseridos passa } \\
\text { para o forno, de forma que a pasta de solda } \\
\text { derreta e fixe os componentes. }\end{array}$ & $\begin{array}{l}\text { Exaustão de gases na } \\
\text { atmosfera. }\end{array}$ & $\begin{array}{l}\text { Alteração da qualidade } \\
\text { do ar. Prejuízo para a } \\
\text { saúde humana, fauna e } \\
\text { flora. }\end{array}$ \\
\hline 6. Revisão 1 & $\begin{array}{l}\text { A placa é revisada visualmente, de forma a } \\
\text { detectar danos ou falhas na montagem. }\end{array}$ & - & - \\
\hline $\begin{array}{l}\text { 7. Inserção } \\
\text { manual de } \\
\text { componentes }\end{array}$ & $\begin{array}{c}\text { Os componentes de maior tamanho ou com } \\
\text { materiais plásticos são inseridos manualmente. }\end{array}$ & - & - \\
\hline 8. Forno 2 & $\begin{array}{c}\text { A placa com os componentes de maior } \\
\text { tamanho ou plásticos inseridos passa para o } 2^{\circ} \\
\text { forno, de forma que a solda presente neste } \\
\text { forno fixe-os. }\end{array}$ & $\begin{array}{c}\text { Descarte de resíduos de } \\
\text { solda e exaustão de gases } \\
\text { na atmosfera. }\end{array}$ & $\begin{array}{l}\text { Alteração da qualidade } \\
\text { do solo, água e ar. } \\
\text { Prejuízo para a saúde } \\
\text { humana, fauna e flora. }\end{array}$ \\
\hline 9. Revisão 2 & $\begin{array}{l}\text { As placas são revisadas na saída do } 2^{\circ} \text { forno, } \\
\text { de forma a eliminar os terminais eletrônicos } \\
\text { dos componentes e resíduos de solda. }\end{array}$ & $\begin{array}{l}\text { Descarte de resíduos de } \\
\text { solda. }\end{array}$ & $\begin{array}{l}\text { Alteração da qualidade } \\
\text { do solo e da água. } \\
\text { Prejuízo para a saúde } \\
\text { humana, fauna e flora. }\end{array}$ \\
\hline 10. Testes & $\begin{array}{l}\text { As placas são testadas em todas as suas } \\
\text { funções, para detectar possíveis defeitos no } \\
\text { processo produtivo. }\end{array}$ & - & - \\
\hline $\begin{array}{c}\text { 11. Serialização/ } \\
\text { embalagem }\end{array}$ & $\begin{array}{c}\text { As placas aprovadas são serializadas e } \\
\text { embaladas em embalagens anti- estáticas e } \\
\text { caixas apropriadas. }\end{array}$ & - & - \\
\hline 12. Reparo & $\begin{array}{c}\text { As placas reprovadas no processo produtivo } \\
\text { passam por novos testes, e são consertadas por } \\
\text { uma equipe técnica. }\end{array}$ & $\begin{array}{l}\text { Descarte de resíduos de } \\
\text { solda e eletrônicos. }\end{array}$ & $\begin{array}{l}\text { Alteração da qualidade } \\
\text { do solo e da água. } \\
\text { Prejuízo para a saúde } \\
\text { humana, fauna e flora. }\end{array}$ \\
\hline 13. Uso geral & $\begin{array}{c}\text { Energia elétrica para equipamentos e } \\
\text { iluminação, água para uso geral, produtos } \\
\text { químicos para limpeza e uso de compressor de } \\
\text { ar. }\end{array}$ & \begin{tabular}{|c} 
Descarte de lâmpadas \\
fluorescentes, o consumo \\
de energia elétrica, \\
descarte de embalagens de \\
produtos de limpeza e \\
descarte do óleo do \\
compressor de ar.
\end{tabular} & $\begin{array}{l}\text { Alteração da qualidade } \\
\text { do solo, do ar, e da água. } \\
\text { Aumento na demanda de } \\
\text { energia elétrica. Prejuízo } \\
\text { para a saúde humana, } \\
\text { fauna e flora. }\end{array}$ \\
\hline
\end{tabular}

Fonte: Pesquisa de campo (2011) 
A Produção SMD/PTH conta com um total de 48 funcionários, distribuídos em três turnos de funcionamento, e sua capacidade estimada de produção é de 120.000 pentes de memória RAM, ou 8.400 placas mãe para microcomputadores portáteis, ou 14.400 placas mãe para microcomputadores por mês. As etapas deste processo produtivo que demandam maior atenção quanto aos aspectos e impactos ambientais são as máquinas de inserção de componentes, fornos, revisão e reparo, pois compreendem a geração de resíduos de solda, pasta de solda, eletrônicos, e emissão de gases, sendo motivo de preocupação por parte da empresa, pela necessidade de um controle rígido dos rejeitos que podem causar danos graves ao meio ambiente, devido a sua composição química.

O processo de produção de microcomputadores e microcomputadores portáteis, e os aspectos e impactos resultantes seguem discriminados no Quadro 6.

Quadro 6 - Etapas do processo produtivo de microcomputadores e microcomputadores portáteis

\begin{tabular}{|c|c|c|c|}
\hline Etapas & Descrição & Aspectos & Impactos \\
\hline \begin{tabular}{|c|}
1. \\
Recebimento \\
de Material e \\
serialização
\end{tabular} & $\begin{array}{l}\text { Matéria-prima é recebida, registrada } \\
\text { no sistema da empresa e serializada. }\end{array}$ & $\begin{array}{c}\text { Descarte de } \\
\text { papel/papelão, isopores, espumas e } \\
\text { plástico das embalagens das } \\
\text { matérias primas. }\end{array}$ & $\begin{array}{l}\text { Alteração da qualidade do } \\
\text { solo. } \\
\text { Prejuízo para a fauna e } \\
\text { flora. }\end{array}$ \\
\hline $\begin{array}{l}\text { 2. Separação } \\
\text { de material e } \\
\text { controle de } \\
\text { seriais }\end{array}$ & $\begin{array}{c}\text { A matéria-prima é separada conforme } \\
\text { os pedidos de venda aprovados para } \\
\text { montagem, de forma a montar um kit } \\
\text { de peças que integram o item. }\end{array}$ & - & - \\
\hline 3. Tampografia & $\begin{array}{l}\text { Com o cliente definido, o processo de } \\
\text { tampografia estampa a logomarca do } \\
\text { cliente no item e nos periféricos. }\end{array}$ & $\begin{array}{c}\text { Descarte de resíduos } \\
\text { de tinta, solventes, diluentes, } \\
\text { catalisadores e papéis contaminados. }\end{array}$ & $\begin{array}{c}\text { Alteração da qualidade do } \\
\text { solo e da água. Prejuízo } \\
\text { para a saúde humana, fauna } \\
\text { e flora. }\end{array}$ \\
\hline $\begin{array}{c}\text { 4. Alimentação } \\
\text { de postos de } \\
\text { trabalho } \\
\end{array}$ & $\begin{array}{l}\text { Os itens são distribuídos nos postos de } \\
\text { trabalho da linha de montagem. }\end{array}$ & - & - \\
\hline 5. Montagem & $\begin{array}{c}\text { Os montadores integram as peças em } \\
\text { uma montagem em série, de forma } \\
\text { que cada montador controle apenas } \\
\text { uma etapa da montagem. }\end{array}$ & \begin{tabular}{|c|} 
Descarte de resíduos de \\
papel/papelão e plástico de algumas \\
embalagens de peças, e metal dos \\
gabinetes de microcomputadores.
\end{tabular} & $\begin{array}{c}\text { Alteração da qualidade do } \\
\text { solo. Prejuízo para a fauna } \\
\text { e flora. }\end{array}$ \\
\hline $\begin{array}{l}\text { 6. Testes } \\
\text { (Burn-In) }\end{array}$ & $\begin{array}{c}\text { Os itens passam por uma bateria de } \\
\text { testes, onde todas as suas funções são } \\
\text { testadas exaustivamente à procura de } \\
\text { falhas de montagem ou de peças. } \\
\end{array}$ & - & - \\
\hline $\begin{array}{l}\text { 7. Controle de } \\
\text { Qualidade e } \\
\text { Inspeção }\end{array}$ & $\begin{array}{c}\text { Depois de testados, uma porcentagem } \\
\text { dos itens é inspecionada para verificar } \\
\text { a presença de outras falhas, ou de } \\
\text { problemas físicos. }\end{array}$ & - & - \\
\hline 8. Embalagem & $\begin{array}{c}\text { Caso sejam aprovados, os itens são } \\
\text { embalados com plásticos apropriados, } \\
\text { e encaixotados. }\end{array}$ & $\begin{array}{l}\text { Descarte de resíduos de } \\
\text { papel/papelão e plástico. }\end{array}$ & \begin{tabular}{|c|}
$\begin{array}{c}\text { Alteração da qualidade do } \\
\text { solo. Prejuízo para a fauna } \\
\text { e flora. }\end{array}$ \\
\end{tabular} \\
\hline 9. Reparo & $\begin{array}{c}\text { Os itens reprovados no processo } \\
\text { produtivo passam por novos testes, e } \\
\text { são consertados por uma equipe } \\
\text { técnica. }\end{array}$ & Descarte de resíduo eletrônico. & \begin{tabular}{|c}
$\begin{array}{c}\text { Alteração da qualidade do } \\
\text { solo e da água. Prejuízo } \\
\text { para a saúde humana, fauna } \\
\text { e flora. }\end{array}$ \\
\end{tabular} \\
\hline 10. Uso geral & $\begin{array}{l}\text { Energia elétrica para equipamentos e } \\
\text { iluminação, água para uso geral, } \\
\text { produtos químicos para limpeza e uso } \\
\text { de compressor de ar. }\end{array}$ & $\begin{array}{l}\text { Descarte de lâmpadas fluorescentes, } \\
\text { o consumo de energia elétrica, } \\
\text { descarte de embalagens de produtos } \\
\text { de limpeza e descarte do óleo do } \\
\text { compressor de ar. }\end{array}$ & $\begin{array}{c}\text { Alteração da qualidade do } \\
\text { solo, do ar, e da água. } \\
\text { Aumento na demanda de } \\
\text { energia elétrica. Prejuízo } \\
\text { para a saúde humana, fauna } \\
\text { e flora. }\end{array}$ \\
\hline
\end{tabular}

Fonte: Pesquisa de campo (2011) 
A Produção Fine Assembly conta com um total de 40 funcionários, distribuídos em dois turnos de funcionamento, e sua capacidade estimada de produção é de 12.000 microcomputadores, ou 8.400 microcomputadores portáteis por mês. As etapas deste processo produtivo que demandam maior atenção quanto aos aspectos e impactos ambientais são a tampografia e reparo, pois compreendem a geração de resíduos de eletrônicos, e de tinta, solventes, diluentes, catalisadores e papéis contaminados, que são causadores potenciais de poluição e danos ao meio ambiente.

\subsection{Avaliação dos processos produtivos com o uso da ferramenta FMEA}

Considerando que ambos os processos produtivos apresentam etapas semelhantes e com o intuito de evitar repetições na identificação destes adotou-se "Processo 1" para Produção SMD/PTH, "Processo 2" para Produção Fine Assembly, e "Processo 1 e 2" para ambos, ver Quadro 7.

Quadro 7 - FMEA aplicado aos processos produtivos da empresa

\begin{tabular}{|c|c|c|c|c|c|c|c|c|c|}
\hline \multirow{2}{*}{$\begin{array}{l}\text { Etapas do } \\
\text { processo }\end{array}$} & \multirow{2}{*}{$\begin{array}{l}\text { Resíduos } \\
\text { gerados }\end{array}$} & \multirow{2}{*}{$\begin{array}{c}\text { Causa } \\
\text { potencial }\end{array}$} & \multicolumn{2}{|c|}{ Identificação } & \multicolumn{4}{|c|}{ Avaliação } & \multirow{2}{*}{$\begin{array}{l}\text { Intensi- } \\
\text { dade do } \\
\text { impacto }\end{array}$} \\
\hline & & & Aspectos & Impactos & M & $\mathrm{F}$ & V & $\mathrm{T}$ & \\
\hline $\begin{array}{l}\text { Recebimento } \\
\text { de materiais/ } \\
\text { embalagem } \\
\text { (processos } 1 \\
\text { e 2) }\end{array}$ & $\begin{array}{l}\text { Papel e } \\
\text { papelão }\end{array}$ & $\begin{array}{c}\text { Descarte } \\
\text { inadequado; } \\
\text { Não } \\
\text { reciclagem }\end{array}$ & $\begin{array}{l}\text { Descarte de } \\
\text { resíduo de } \\
\text { papel e } \\
\text { papelão }\end{array}$ & $\begin{array}{l}\text { Contaminação } \\
\text { do solo }\end{array}$ & 1 & 1 & 2 & 4 & Média \\
\hline $\begin{array}{l}\text { Recebimento } \\
\text { de material } \\
\text { (processos. } 1 \\
\text { e 2) }\end{array}$ & Isopor & $\begin{array}{c}\text { Descarte } \\
\text { inadequado; } \\
\text { Não } \\
\text { reciclagem }\end{array}$ & $\begin{array}{l}\text { Descarte de } \\
\text { resíduo de } \\
\text { isopor }\end{array}$ & $\begin{array}{l}\text { Contaminação } \\
\text { do solo; Danos } \\
\text { à fauna e a } \\
\text { flora. }\end{array}$ & 1 & 1 & 1 & 3 & Baixa \\
\hline $\begin{array}{l}\text { Recebimento } \\
\text { de material } \\
\text { (processos } 1 \\
\text { e 2) }\end{array}$ & Espuma & $\begin{array}{c}\text { Descarte } \\
\text { inadequado; } \\
\text { Não } \\
\text { reciclagem }\end{array}$ & $\begin{array}{l}\text { Descarte de } \\
\text { resíduo de } \\
\text { espuma }\end{array}$ & $\begin{array}{l}\text { Contaminação } \\
\text { do solo; Danos } \\
\text { à fauna e a } \\
\text { flora. }\end{array}$ & 1 & 1 & 1 & 3 & Baixa \\
\hline $\begin{array}{l}\text { Recebimento } \\
\text { de material, } \\
\text { mont agem e } \\
\text { embalagem } \\
\text { (processos } 1 \\
\text { e 2) } \\
\end{array}$ & Plástico & $\begin{array}{c}\text { Descarte } \\
\text { inadequado; } \\
\text { Não } \\
\text { reciclagem }\end{array}$ & $\begin{array}{l}\text { Descarte de } \\
\text { resíduo de } \\
\text { plástico }\end{array}$ & $\begin{array}{l}\text { Contaminação } \\
\text { do solo; Danos } \\
\text { à fauna e a } \\
\text { flora. }\end{array}$ & 1 & 1 & 1 & 3 & Baixa \\
\hline $\begin{array}{l}\text { Montagem } \\
\text { (processo2) }\end{array}$ & Metal & $\begin{array}{c}\text { Descarte } \\
\text { inadequado; } \\
\text { Não } \\
\text { reciclagem }\end{array}$ & $\begin{array}{l}\text { Descarte de } \\
\text { resíduo de } \\
\text { metal }\end{array}$ & $\begin{array}{l}\text { Contaminação } \\
\text { do solo }\end{array}$ & 1 & 1 & 1 & 3 & Baixa \\
\hline $\begin{array}{l}\text { Tampografia } \\
\text { (processo 2) }\end{array}$ & $\begin{array}{c}\text { Resíduos } \\
\text { de tinta, } \\
\text { solvente, } \\
\text { diluente, } \\
\text { catalisador } \\
\text { e papel } \\
\text { contaminad } \\
\text { o }\end{array}$ & $\begin{array}{c}\text { Descarte } \\
\text { inadequado; } \\
\text { derramamento } \\
\text { acidental }\end{array}$ & $\begin{array}{l}\text { Descarte de } \\
\text { resíduo de } \\
\text { tinta, solvente, } \\
\text { diluente, } \\
\text { catalisador e } \\
\text { papel } \\
\text { contaminado }\end{array}$ & $\begin{array}{l}\text { Contaminação } \\
\text { do solo e da } \\
\text { água; danos à } \\
\text { saúde humana } \\
\text { e a fauna e } \\
\text { flora }\end{array}$ & 3 & 1 & 1 & 5 & Média \\
\hline $\begin{array}{l}\text { Máquinas de } \\
\text { inserção, } \\
\text { fornos, } \\
\text { revisão e }\end{array}$ & $\begin{array}{c}\text { Resíduo de } \\
\text { solda e } \\
\text { pasta de } \\
\text { solda }\end{array}$ & $\begin{array}{c}\text { Descarte } \\
\text { inadequado; } \\
\text { falta de } \\
\text { manutenção }\end{array}$ & $\begin{array}{c}\text { Descarte de } \\
\text { resíduo de } \\
\text { solda e pasta de } \\
\text { solda }\end{array}$ & $\begin{array}{l}\text { Contaminação } \\
\text { do solo e da } \\
\text { água; danos à } \\
\text { saúde humana }\end{array}$ & 3 & 2 & 2 & 7 & Alta \\
\hline
\end{tabular}




\begin{tabular}{|c|c|c|c|c|c|c|c|c|c|}
\hline $\begin{array}{c}\text { reparos } \\
\text { (processo 1) }\end{array}$ & & & & $\begin{array}{l}\text { e a fauna e } \\
\text { flora }\end{array}$ & & & & & \\
\hline $\begin{array}{c}\text { Reparo } \\
\text { (processos } 1 \\
\text { e 2) }\end{array}$ & $\begin{array}{c}\text { Peças e } \\
\text { component } \\
\text { es } \\
\text { eletrônicos }\end{array}$ & $\begin{array}{c}\text { Descarte } \\
\text { inadequado; } \\
\text { Não } \\
\text { reciclagem }\end{array}$ & $\begin{array}{l}\text { Descarte de p } \\
\text { Peças e } \\
\text { componentes } \\
\text { eletrônicos }\end{array}$ & $\begin{array}{l}\text { Contaminação } \\
\text { do solo e da } \\
\text { água; danos à } \\
\text { saúde humana } \\
\text { e a fauna e } \\
\text { flora }\end{array}$ & 3 & 2 & 2 & 7 & Alta \\
\hline $\begin{array}{c}\text { Fornos } \\
\text { (processo 1) }\end{array}$ & Gases & $\begin{array}{l}\text { Não uso de } \\
\text { filtros nos } \\
\text { equipamentos; } \\
\text { falta de } \\
\text { manutenção }\end{array}$ & $\begin{array}{c}\text { Emissão de } \\
\text { gases na } \\
\text { atmosfera }\end{array}$ & $\begin{array}{l}\text { Alteração da } \\
\text { qualidade do } \\
\text { ar; danos à } \\
\text { saúde humana } \\
\text { e a fauna e } \\
\text { flora }\end{array}$ & 3 & 3 & 1 & 7 & Alta \\
\hline \multirow{4}{*}{$\begin{array}{c}\text { Uso geral } \\
\text { (processos } 1 \\
\text { e } 2 \text { ) }\end{array}$} & $\begin{array}{c}\text { Óleo } \\
\text { lubrificante }\end{array}$ & $\begin{array}{c}\text { Descarte } \\
\text { inadequado; } \\
\text { derramamento } \\
\text { acidental; não } \\
\text { reciclagem }\end{array}$ & $\begin{array}{l}\text { Descarte do } \\
\text { óleo } \\
\text { lubrificante do } \\
\text { compressor de } \\
\quad \text { ar }\end{array}$ & $\begin{array}{c}\text { Contaminação } \\
\text { do solo e do } \\
\text { ar; } \\
\text { envenenament } \\
\text { o dos lençóis } \\
\text { freáticos; } \\
\text { danos à saúde } \\
\text { humana, fauna } \\
\text { e flora } \\
\end{array}$ & 3 & 1 & 3 & 7 & Alta \\
\hline & $\begin{array}{c}\text { Embalagen } \\
\text { s e resíduos } \\
\text { de produtos } \\
\text { de limpeza }\end{array}$ & $\begin{array}{c}\text { Descarte } \\
\text { inadequado; } \\
\text { derramamento } \\
\text { acidental }\end{array}$ & $\begin{array}{l}\text { Descarte de } \\
\text { embalagens e } \\
\text { resíduos de } \\
\text { produtos de } \\
\text { limpeza }\end{array}$ & $\begin{array}{c}\text { Contaminação } \\
\text { do solo e dos } \\
\text { lençóis } \\
\text { freáticos }\end{array}$ & 1 & 1 & 1 & 4 & Baixa \\
\hline & $\begin{array}{l}\text { Consumo } \\
\text { de energia } \\
\text { elétrica }\end{array}$ & $\begin{array}{l}\text { Funcionament } \\
\text { o contínuo de } \\
\text { equipamentos } \\
\text { e lâmpadas }\end{array}$ & $\begin{array}{l}\text { Consumo de } \\
\text { energia elétrica }\end{array}$ & $\begin{array}{c}\text { Aumento da } \\
\text { demanda de } \\
\text { energia elétrica }\end{array}$ & 1 & 1 & 1 & 3 & Baixa \\
\hline & $\begin{array}{c}\text { Lâmpadas } \\
\text { fluorescent } \\
\text { e }\end{array}$ & $\begin{array}{c}\text { Descarte } \\
\text { inadequado; } \\
\text { Não } \\
\text { reciclagem }\end{array}$ & $\begin{array}{l}\text { Descarte de } \\
\text { lâmpadas } \\
\text { fluorescente }\end{array}$ & $\begin{array}{l}\text { Contaminação } \\
\text { do solo e do } \\
\text { ar; } \\
\text { envenenament } \\
\text { o dos lençóis } \\
\text { freáticos; } \\
\text { danos à fauna } \\
\text { e flora }\end{array}$ & 3 & 1 & 1 & 5 & Média \\
\hline
\end{tabular}

Fonte: Pesquisa de campo (2011)

De acordo com a Quadro 7, foram identificados 13 tipos de resíduos gerados pelas atividades produtivas da Empresa $\mathrm{X}$, dentre os quais apenas 6 foram conceituados como um impacto de baixa intensidade, 3 conceituados como de média ou moderada intensidade, e 4 como alta intensidade, demonstrando que cerca de 54\% destes tipos de resíduos, e seus impactos potenciais devem ser analisados com cautela para a tomada de medidas ambientalmente corretas, visto que são de média a alta intensidade. Para todos os impactos levantados, a empresa possui ações implantadas, ou em implantação, condizentes com as ações de controle ou correção, o que demonstra a sua preocupação em manter um controle dos resíduos gerados em seus processos produtivos.

A geração de resíduos de isopor, espuma, plástico, metal, embalagem de produtos de limpeza, e consumo de energia elétrica obtiveram um total de 3 pontos, sendo conceituada com 
uma intensidade do impacto considerada baixa, devido sua pontuação quanto à magnitude dos impactos gerados, a frequência de acontecimento destes, e o volume dos resíduos. Os resíduos de isopor, por serem gerados em pouca quantidade no processo de separação de materiais, são quebrados ou triturados, e totalmente reaproveitados no próprio processo produtivo, e em outros processos de venda, na embalagem de microcomputadores, microcomputadores portáteis e periféricos, devido à sua capacidade de isolamento e proteção contra impactos. O mesmo acontece com as espumas, as quais são fragmentadas de acordo com o seu tamanho, e inseridas na embalagem dos produtos, o que caracteriza a total eliminação de ambos os resíduos, e conseqüentemente dos seus respectivos impactos potenciais.

Quanto aos plásticos, todos os resíduos são coletados nos processos de separação de materiais, montagem e embalagem, e acondicionados em lixeiras específicas. Os plásticos flexíveis, semelhantes a sacolas, são armazenados em caixas, que são coletadas mensalmente por uma cooperativa localizada na própria cidade de Campina Grande, que realiza a reciclagem ou venda do material. Em média, o volume total destes plásticos é de $210 \mathrm{Kg}$ mensais. Os plásticos rígidos, que são gerados em pequena quantidade (cerca de $40 \mathrm{Kg}$ mensais), são armazenados em uma área externa da empresa, porém não são reciclados, pois as instituições de coleta locais para reciclagem não trabalham com este tipo de material. Assim, a Empresa realiza o descarte através do sistema municipal de coleta de lixo, e está no momento desenvolvendo uma parceria com uma empresa pernambucana, de forma a realizar o processo correto de destinação. Deste modo, a eliminação dos resíduos de plástico é considerada parcial, assim como é parcial a eliminação dos impactos potenciais.

Os resíduos de metais também são totalmente coletados no processo de produção de microcomputadores e microcomputadores portáteis, durante a montagem dos gabinetes dos equipamentos. Os resíduos de chapas metálicas e rebites, que correspondem a uma média $380 \mathrm{Kg}$ mensais, são encaixotados e separados em um local específicos da empresa. Mensalmente, uma sucata e uma cooperativa localizadas na própria cidade de Campina Grande, realizam a coleta de todo o material para realizar a reciclagem ou venda, o que caracteriza a total eliminação dos resíduos, e conseqüentemente dos impactos potenciais.

Quanto às embalagens de produtos de limpeza, estas são devidamente separadas durante a coleta seletiva, após o consumo total, perfazendo uma média de $7 \mathrm{Kg}$ de embalagens mensais. Não existe uma preocupação com os produtos químicos existentes, pois estes produtos de limpeza apresentam-se como biodegradáveis, de acordo com as informações existentes nas embalagens, disponibilizadas pelos próprios fabricantes. Porém a empresa não destina as embalagens para entidades que realizem a reciclagem do material, descartando-as junto ao sistema municipal de coleta de lixo. Assim, a eliminação das embalagens de produtos de 
limpeza, bem como a eliminação dos impactos potenciais não é realizada pela empresa.

Quanto ao consumo de energia elétrica, apesar de ser classificado como um impacto de baixa intensidade recebe uma atenção especial. Como os processos produtivos são contínuos, funcionando em três turnos, exigindo que as máquinas, esteiras, computadores de usuários, lâmpadas e postos de testes estejam sempre em funcionamento, tem-se dificuldade em adotar medidas de redução de consumo. A empresa está adquirindo equipamentos de medição e monitoramento do consumo de energia, que serão instalados individualmente em todos os setores, tanto produtivos como administrativos. Assim ela pretende detectar os pontos de maior e menor consumo, de forma a planejar medidas e adquirir equipamentos que possam reduzir o consumo. Apesar desta dificuldade, a empresa mantém informativos afixados nos diversos ambientes de trabalho, que funcionam como lembretes para os funcionários, de forma a conscientizá-los quanto à economia de energia, e os benefícios tanto para a empresa, quanto para o meio ambiente. Assim, a eliminação do impacto potencial do consumo de energia é considerada parcial.

A geração de resíduos de papel/papelão, tinta, solvente, diluentes, catalisador, papéis contaminados, e lâmpadas fluorescentes obtiveram uma pontuação equivalente à conceituação de intensidade do impacto média ou moderada. Os resíduos de papel/papelão, que geram uma média de $1.200 \mathrm{Kg}$ mensais, são recolhidos nos processos de separação material, montagem e embalagem, e separados devidamente em uma área específica da empresa através da coleta seletiva. Os papelões, que correspondem a uma média de $950 \mathrm{Kg}$, são coletados mensalmente por uma cooperativa localizada na própria cidade de Campina Grande, que faz a reciclagem do material. Os demais papéis gerados nos processos produtivos são separados, e a Empresa realiza o descarte através do sistema municipal de coleta de lixo, e não desenvolve nenhum programa para reciclagem do material, apesar de ter evidenciado a procura por parte da empresa por cooperativas que possam realizar o processo. Dessa forma, a eliminação dos resíduos de papel/papelão, bem como, a potencialidade do impacto, são considerados parciais.

Quanto às tintas, solventes, diluentes, catalisadores e papéis contaminados, a empresa adotou a documentação disponibilizada pelo fornecedor dos produtos, denominada FISPQ (Ficha de Informações de Segurança de Produto Químico), que indicam as melhores formas de tratamento e destinação dos resíduos dos produtos químicos, para desenvolver suas práticas internas. Em geral, estas práticas consistem em armazenar as embalagens e resíduos dos produtos químicos em latões de aço, e providenciar o descarte junto ao fornecedor ou a entidades governamentais. Porém, a empresa ainda está desenvolvendo uma parceria com o próprio fornecedor dos produtos, localizado na cidade de São Paulo/SP, para a correta destinação dos materiais de forma mensal, porém, sem que haja custos adicionais para a mesma. 
Dessa forma, está sendo necessária a armazenagem momentânea até que este impasse seja solucionado. Assim, a eliminação do potencial impacto, e a eliminação dos resíduos são consideradas parciais.

No caso das lâmpadas fluorescentes, estas são separadas em lixeira apropriada, e em local isolado dos funcionários da empresa, de forma a evitar quebras acidentais ou contaminação, com uma média de 3,3 Kg (ou 11 lâmpadas) mensais, considerado um baixo volume de resíduos. Apesar dos riscos envolvidos com o manuseio de lâmpadas, a Empresa ainda estuda a parceria com uma empresa pernambucana para coleta deste material. Porém, as empresas de coleta de lâmpadas realizam este serviço apenas quando existe uma disponibilidade mínima de resíduos, com média superior a 350 lâmpadas. Assim, a Empresa mantém a coleta e armazenagem, que caracterizam uma eliminação parcial do impacto potencial e dos resíduos.

A geração de resíduos de solda e pasta de solda, peças e componentes eletrônicos, óleo, e emissão de gases obtiveram uma pontuação igual ou superior a 7 pontos, o que equivale à conceituação de intensidade do impacto alta, principalmente por causa da alta magnitude dos impactos, e moderados volumes e freqüências de geração dos resíduos. Nestes casos, o tratamento que deve ser dado pela empresa em relação aos resíduos gerados é de extrema importância para que os impactos para o meio ambiente não sejam irreversíveis ou de grande extensão.

Os resíduos de solda e pasta de solda são armazenados de acordo com suas FISPQs (Ficha de Informações de Segurança de Produto Químico), o que obriga a e mpresa a utilizar os recipientes vindos dos fabricantes para esta coleta. Mensalmente, são gerados de $550 \mathrm{Kg}$ de rejeitos em média. Todos os resíduos de solda, também chamados de "borra de solda", são acondicionados em latas de metal específicas para o material, fornecidas juntamente com a matéria-prima. A cada 2 meses, esse material é enviado para o fornecedor, localizado na cidade de São Paulo - SP, servindo como moeda de troca na aquisição de nova solda beneficiada. A pasta de solda recebe o mesmo tratamento, porém é enviada para um fornecedor localizado na cidade de Manaus - AM, para que seja realizado o descarte correto do material, neste caso, a pasta não serve como moeda de troca. Dessa forma, o impacto potencial e os resíduos de solda e pasta de solda são eliminados totalmente.

Os resíduos eletrônicos são separados durante o processo de reparo, onde há o descarte do material apresentado com defeito e sem possibilidade de reparo, contemplando componentes eletrônicos, fios e cabos, placas de circuito impresso, mouses, teclados, etc. Estes resíduos são colocados em lixeiras identificadas especificamente para este fim. Após esta separação, os resíduos são encaixotados, pesados e devidamente identificados, e depois armazenados em uma área específica do estoque da Empresa. Assim, os resíduos são 
destinados a uma empresa paraibana localizada na cidade de Bayeux - PB, com uma periodicidade média de 3 meses, onde são descaracterizados e segregados de acordo com os tipos de material, sendo posteriormente enviados para empresas no exterior do país que realizam o reaproveitamento. Assim, os impactos potenciais e os resíduos são eliminados

\section{totalmente.}

Os resíduos de óleo lubrificante são recolhidos e armazenados em tambores, em uma área externa da empresa devidamente isolada e protegida contra vazamentos. Dos $15 \mathrm{~L}$ de óleo lubrificantes gerados mensalmente, apenas $4 \mathrm{~L}$ ou $5 \mathrm{~L}$ são coletados por uma loja da própria cidade de Campina Grande, que comercializa equipamentos e ferramentas agrícolas, reutilizando o óleo para lubrificar os motores dos seus produtos. Esta loja faz a coleta de forma não formal, no momento da manutenção trimestral do compressor de ar da empresa. A empresa está buscando convencer a loja com a coleta total dos resíduos, gerando um certificado que ateste o processo e o compromisso ambiental de ambas as partes. Assim, os impactos potenciais, e os resíduos de óleo lubrificante são eliminados parcialmente.

Quanto à emissão de gases, a empresa contratou uma instituição localizada na própria cidade de Campina Grande, que realizou um teste nas chaminés dos equipamentos que emitem gases na atmosfera, constatando que existe a emissão constante de uma pequena quantidade de elementos químicos nocivos. Porém, a instituição não emitiu um laudo final, que pudesse demonstrar quais elementos estão sendo expelidos, e quais as medidas cabíveis para o caso. A Empresa X, por sua vez, realiza a manutenção periódica dos equipamentos, e a devida limpeza das chaminés, de forma a evitar acúmulos prejudiciais, e aguarda a posição final da instituição responsável pela medição da emissão, para realizar o correto controle desse aspecto. Em contato prévio com o fornecedor dos equipamentos que contém as chaminés, ficou esclarecido pelos mesmos que a emissão de poluentes é mínima, não sendo suficiente para contaminar o ar. Dessa forma, os impactos potenciais, e os resíduos não são eliminados pela empresa.

A partir destes resultados, pode-se elaborar um resumo, ver Quadro 8, considerando a intensidade do impacto potencial, os resíduos, os volumes gerado e reciclado, e o resultado das ações da empresa diante dos resíduos gerados e do impacto potencial.

Quadro 8 - Resumo de resíduos, volumes gerados e reciclados, e ações da empresa

\begin{tabular}{|c|c|c|c|c|}
\hline $\begin{array}{c}\text { Intensidade } \\
\text { do impacto } \\
\text { potencial }\end{array}$ & Resíduos & $\begin{array}{c}\text { Volume } \\
\text { médio } \\
\text { mensal } \\
\text { gerado }\end{array}$ & $\begin{array}{c}\text { Volume médio } \\
\text { mensal } \\
\text { reciclado ou } \\
\text { destinado } \\
\text { corretamente }\end{array}$ & $\begin{array}{c}\text { Resultado das ações da } \\
\text { empresa }\end{array}$ \\
\hline \multirow{3}{*}{ Baixa } & Isopor & 20 & $20 \mathrm{Kg}$ & Eliminado totalmente \\
\cline { 2 - 5 } & Espuma & 18 & $18 \mathrm{Kg}$ & Eliminado totalmente \\
\cline { 2 - 5 } & Plástico & $250 \mathrm{Kg}$ & $210 \mathrm{Kg}$ & Eliminado parcialmente \\
\hline
\end{tabular}




\begin{tabular}{|c|c|c|c|c|}
\hline & Metal & $380 \mathrm{Kg}$ & $380 \mathrm{Kg}$ & Eliminado totalmente \\
\hline & $\begin{array}{l}\text { Embalagens e resíduos de } \\
\text { produtos de limpeza }\end{array}$ & $7 \mathrm{Kg}$ & $0 \mathrm{Kg}$ & Não eliminado \\
\hline & Consumo de energia elétrica & Não informado & Não informado & Eliminado parcialmente \\
\hline \multirow{3}{*}{$\begin{array}{l}\text { Média ou } \\
\text { Moderada }\end{array}$} & Papel/Papelão & $1.200 \mathrm{Kg}$ & $950 \mathrm{Kg}$ & Eliminado parcialmente \\
\hline & $\begin{array}{c}\text { Tinta, solvente, diluente, } \\
\text { catalisador e papel } \\
\text { contaminado }\end{array}$ & $\begin{array}{l}10 \\
\mathrm{Kg}\end{array}$ & $0 \mathrm{Kg}$ & Eliminado parcialmente \\
\hline & Lâmpadas fluorescentes & $3,3 \mathrm{Kg}$ & $0 \mathrm{Kg}$ & Eliminado parcialmente \\
\hline \multirow{4}{*}{ Alta } & $\begin{array}{c}\text { Resíduos de solda e pasta de } \\
\text { solda }\end{array}$ & $550 \mathrm{Kg}$ & $550 \mathrm{Kg}$ & Eliminado totalmente \\
\hline & $\begin{array}{l}\text { Peças e componentes } \\
\text { eletrônicos }\end{array}$ & $1.200 \mathrm{Kg}$ & $1.200 \mathrm{Kg}$ & Eliminado totalmente \\
\hline & Gases & Não informado & Não informado & Não eliminado \\
\hline & Óleo lubrificante & $15 \mathrm{~L}$ & $5 \mathrm{~L}$ & Eliminado parcialmente \\
\hline
\end{tabular}

Fonte: Pesquisa de campo (2011)

A seguir serão apresentadas as considerações finais.

\section{Considerações finais}

Os impactos ambientais gerados pela empresa estudada foram avaliados com uso da ferramenta FMEA. Dessa forma, foi constatado que a empresa estudada mantém diversas práticas ambientais em relação aos resíduos gerados em seu processo produtivo, de forma voluntária, quando se tratam, por exemplo, de papelões, plásticos, metal, resíduos eletrônicos e lâmpadas; por questões econômicas, quando se tratam de resíduos de solda, ao servirem como moeda de troca para a empresa, ou por pressões da legislação, quando se tratam, por exemplo, de resíduos de produtos químicos que não podem ser descartados de qualquer maneira. Com essas práticas a empresa também busca a adequação às normas ambientais, visto que se encontra em fase de implantação de seu Sistema de Gestão Ambiental, que fornecerá uma imagem de empresa ambientalmente responsável, a qual será revertida em melhoria de sua competitividade.

Porém, a empresa se depara com algumas dificuldades para encontrar organizações e cooperativas dispostas e aptas para realizar o serviço de reciclagem de maneira correta. Assim, a empresa acaba utilizando seus recursos de estoque para não descartar de forma inadequada a maioria dos resíduos, tentando contribuir da melhor forma possível com as questões ambientais. Entretanto, alguns resíduos gerados, como os plásticos rígidos e os papéis são descartados diretamente junto ao sistema municipal de coleta de lixo, de forma que o problema acaba sendo apenas transferido para o município, o que vem a colaborar com a poluição e a degradação ambiental.

Cabe ressaltar que o município não dispõe de estrutura para colaborar com as questões ambientais, pois não realiza a coleta de lixo de forma a separar os materiais e destiná-los da forma adequada em aterros sanitários, e o destino final dos materiais acaba sendo em um lixão a 
céu aberto.

O simples fato de tratar os resíduos e destiná-los a empresas de coleta e reciclagem, não descaracteriza os resíduos como fontes de impactos ambientais. Nestes casos, a empresa apenas repassa o problema gerado para que outras instituições façam a reutilização, porém durante este processo de reutilização, muitos desses rejeitos são descartados indevidamente, além do próprio processo gerar novas entradas para indústrias, que reiniciam todo o ciclo de produção e, como consequiência, o processo de degradação ambiental. Dessa forma, o fato dos resultados apontarem a eliminação parcial ou total dos materiais, indica apenas que a eliminação aconteceu até o ponto onde a responsabilidade recai sobre a empresa.

Assim, as informações geradas neste estudo podem contribuir para o setor no sentido de fornecer informações úteis para a redução dos impactos causados pelas atividades das indústrias microeletrônicas, através do correto tratamento dos aspectos inerentes aos processos produtivos, fornecendo também subsídios para que as indústrias possam exigir do poder público soluções quanto à coleta do lixo industrial, combatendo o descarte inadequado e garantindo a sustentabilidade ambiental.

Uma importante contribuição teórica do estudo reside na demonstração da viabilidade do uso da ferramenta FMEA para a análise dos aspectos e impactos ambientais, devido ao seu formato que confere organização ao trabalho realizado, e também a possibilidade de integrar em uma só ferramenta a descrição dos processos e seus respectivos aspectos e impactos, mensurando-os e definindo as práticas a serem utilizadas em cada caso específico. Assim, a ferramenta FMEA pode ser utilizada em diversos ambientes industriais, como a própria indústria microeletrônica. $\mathrm{O}$ estudo também na ampliação do conhecimento sobre os aspectos, impactos e práticas ambientais de indústrias de microeletrônica, pois ainda é relativamente pouco explorada pelos pesquisadores e estudantes da área de gestão ambiental.

Dentre as limitações deste estudo, pôde-se identificar a possibilidade de ampliar os critérios ou parâmetros utilizados para avaliação dos impactos encontrados, adicionando-se outros critérios de avaliação, como por exemplo, o critério de detecção, para medir o nível de facilidade ou não da detecção do impacto potencial.

Quanto às dificuldades do estudo, destacou-se o ato de mensurar precisamente as quantidades de determinados elementos constantes em alguns resíduos, como por exemplo, os resíduos eletrônicos, que podem conter elementos como chumbo, cádmio, belírio e mercúrio, que são tóxicos, e outros não tóxicos como o vidro. Assim, a medição conteve-se apenas no fato do resíduo conter, ou não, certos elementos químicos, sendo suficiente para a sua classificação perante os parâmetros utilizados.

Como sugestão para futuros estudos indica-se a aplicação da FMEA em outras empresas 
do setor de microeletrônica, bem como em quaisquer outros setores, visto que a ferramenta é flexível às especificidades das empresas.

\begin{abstract}
This paper is based on applying the tool of Analysis of Failure Modes and Effects (FMEA) with the aim of identifying environmental aspects and practices in the microelectronics industry. In the theory, shows that the FMEA can be adapted for this purpose in order to analyze the points at which a company may cause environmental damage and what measures should be taken to mitigate these damage. Regarding the methodology used, we conducted a survey characterized as exploratory and descriptive, using the case study. The data were treated qualitatively and quantitatively using the parameters established with the purpose of measuring the environmental impacts, for use with the FMEA tool. Through the application of the tool, we found that the studied company performs various types of disposal of waste chemicals, electronics, packaging and materials used in the production process from its two manufacturing processes, generating 13 different topics and 6 considered of low intensity, 3 medium or moderate and 4 high intensity, among which 2 of the waste and potential impacts are not properly eliminated, 6 are eliminated partially, and 5 are eliminated altogether.
\end{abstract}

Keywords: environmental practices; FMEA; environmental aspects and environmental impacts; microeletronic.

\title{
Referências
}

AGUILAR, F. P. Tecnologia da informação verde: Uma abordagem sobre investimentos e atitudes das empresas para tornar socialmente sustentável o meio ambiente. São Paulo: FATEC, 2009.

ANDRADE, M. R. S.; TURRIONI, J. B. Uma metodologia de análise dos aspectos e impactos ambientais através da utilização do FMEA. In: Encontro nacional de Engenharia de Produção, 20, 2000, São Paulo. Anais... São Paulo: ENEGEP, 2000.

ASSOCIAÇÃO BRASILEIRA DE NORMAS TÉCNICAS. ABNT NBR ISO 14001: sistemas de gestão ambiental requisitos com orientação para uso. Rio de Janeiro, 2004.

HOLZMANN, M. C.; NETO, J. J.; ZANETTI, M. A.; CIMARELLI, C.; JULIO, L. M.; DZIEDZIC, M.; JANISSEK, P. R.; OLIVEIRA, C. M. R. Avaliação do ciclo de vida na indústria eletrônica: Aspectos teóricos e práticos. In: Encontro Nacional sobre Gestão Empresarial e Meio Ambiente, 11, 2009, Fortaleza , Anais.... Fortaleza: ENGEMA, 2009.

LEITE, P. R.; LAVEZ, N.; SOUZA, V. M. Fatores da logística reversa que influem no reaproveitamento do "lixo eletrônico" - Um Estudo no Setor de Informática In: Simpósio de Administração da Produção, Logística e Operações Internacionais, 12, 2009, São Paulo. Anais... São Paulo: SIMPOI, 2009.

MATOS, R. B.; MILAN, M. Aplicação sistêmica do modo de análise de falhas e efeitos (FMEA) para o desenvolvimento de indicadores de desempenho de empresas de pequeno porte. Revista Árvore, Viçosa, v. 33, n. 5, Outubro de 2009.

PUGA, F. P.; JUNIOR, G. B. Perspectiva de investimentos na indústria 2011 - 2014. Visão do Desenvolvimento. BNDES, n. 91, fev. 2011.

SANTOS, E. F.; SOUZA, M. T. S. Um estudo das motivações para implantação de programas de logística reversa de microcomputadores. Revista Eletrônica de Ciência administrativa, v. 8, n. 2, p.137-150, nov. 2009.

STAMATIS, D. H. Failure mode and effect analysis: FMEA from theory to execution. Wisconsin: ASQ Quality Press, 1995. 494 p.

TAVARES, W. M. L. A indústria eletrônica no Brasil e seu impacto sobre a balança comercial. Consultoria 
Legislativa, novembro de 2001.

VANDENBRANDE, W. W. How to use FMEA to reduce the size of your quality toolbox; Quality Progress. v. 31, n. 11, 1998, p. 97-100.

VERGARA, S. C. Projetos e Relatórios de Pesquisa em Administração. São Paulo: Atlas, 2009.

\section{Dados dos autores}

\section{Nome completo: Leandro Nascimento de Oliveira}

Filiação institucional: Universidade Federal de Campina Grande - UFCG

Departamento: Unidade Acadêmica de Administração e Contabilidade

Função ou cargo ocupado: Aluno graduado

Endereço completo para correspondência: Rua José Marinho Falcão, 105, Apto. C303 Bairro:

Bodocongó, Campina Grande / PB - Brasil - CEP: 58430- 768.

Telefones para contato: (83) 8859-5997 / 3310-5700

e-mail: inforleo@gmail.com

Nome completo: Lúcia Santana de Freitas

Filiação institucional: Universidade Federal de Campina Grande - UFCG

Departamento: Unidade Acadêmica de Administração e Contabilidade

Função ou cargo ocupado: Professor Associado

Endereço completo para correspondência: Rua João Machado, 42, Prata, Campina grande, PB Brasil, CEP 58400-510

Telefones para contato: (83) 3342-3859

e-mail: luciasf@ch.ufcg.edu.br

Submetido em: 30/08/2012

Aceito em: 16/12/2013 